\title{
Denegación de incapacidad versus ineptitud laboral
}

\author{
Denial of disability versus inability to meet essential \\ job functions
}

\section{Ambar Deschamps Perdomo ${ }^{1}$}

'Servicio de Prevención Mancomunado Hospitales Universitario Rey Juan Carlos, Infanta Elena y General de Villalba, Madrid, España.

Fechas · Dates

Recibido: 2019.11.05

Aceptado: 2020.02.12

Publicado: 2020.04.15
Correspondencia · Corresponding Author

Ambar Deschamps Perdomo

Servicio de Prevención Mancomunado Hospitales Universitario

Rey Juan Carlos, Infanta Elena y General de Villalba.

Calle Gladiolo s/n 28933 Móstoles, Madrid, España

ambardeschampsp@gmail.com 


\title{
Resumen
}

El retorno al trabajo tras una baja médica prolongada comporta una valoración tanto de la capacidad laboral como de la aptitud para el trabajo. Nos encontramos con una trabajadora auxiliar administrativa con lesión congénita en cuerdas vocales, a quien se le deniega la incapacidad permanente total. Es valorada en el reconocimiento médico tras ausencia prolongada resultando apta con limitaciones. Tras la revisión de la evaluación de riesgos de su puesto y de todos los compatibles con su categoría profesional se procede a despido objetivo por ineptitud sobrevenida. La valoración de la capacidad/incapacidad laboral debe ser una valoración multidisciplinar, contemplando de forma integrada el diagnóstico, el tratamiento, la evolución, la perspectiva preventiva y la laboral.

Palabras clave: Aptitud; Trabajo; Valoración ocupacional; Incapacidad; Incapacidad laboral

\begin{abstract}
The return to work process following a prolonged medical leave includes an assessment of both work capacity and ability to meet essential job functions. We present the case of an administrative assistant with a congenital vocal cord injury who was denied total permanent disability. The initial fitness for duty examination after her prolonged absence resulted in a determination of fitness, but with limitations. After performing a risk assessment and review of the essential job functions of her occupation, she was dismissed based on inability to meet the essential demands of the job. Assessments of work capacity/disability must be multidisciplinary, integrating the diagnosis, treatment, course of the illness, and conducted from both a preventive and work perspective.
\end{abstract}

Keywords: Fitness for duty; work; occupational assessment; disability; work-related disability

\section{Introducción}

El retorno al trabajo tras una baja médica prolongada comporta una valoración tanto de la capacidad laboral como de la aptitud para el trabajo. En algunas ocasiones nos encontramos con trabajadores que no tienen reconocida una incapacidad y resultan no aptos para su puesto de trabajo. Esta controversia de alta médica e ineptitud laboral puede tener su origen en una falta de comunicación entre quienes gestionan los distintos procesos: el Servicio de Prevención de Riesgos Laboral (SPRL en adelante) por un lado y el Servicio Público de Salud por otro(1).

El SPRL es quien conoce las características del puesto de trabajo del trabajador (riesgos y requerimientos de su estado de salud), pero no tiene acceso a su historia clínica ni a la información de su proceso de incapacidad temporal sobrevenido. Por el contrario, los servicios médicos asistenciales (atención primaria y especializada), la Inspección Médica y el Instituto Nacional de la Seguridad Social sí conocen todo el proceso clínico y de incapacidad, pero desconocen los requerimientos, tareas y riesgos específicos del puesto de trabajo. 
Por tanto, los agentes implicados en la valoración de una incapacidad no tienen a su disposición información objetiva de las características del puesto del trabajador salvo por lo que éste les pueda referir o lo que aparezca en el código nacional de ocupación o el grupo de cotización ${ }^{(1-4)}$, lo que puede conducir a las situaciones incongruentes ya mencionadas.

\section{Descripción del caso}

Mujer 41 años a quien se le realiza un Examen de Salud tras ausencia prolongada de su puesto de trabajo (Auxiliar Administrativo desde hace 10 años en la empresa) a quien se le acaba de denegar una incapacidad permanente total.

Presenta desde los 20 años episodios recurrentes de afonía, que siempre se trataron como disfonías funcionales. En el último episodio, al no mejorar con tratamiento con auxina A, se le solicita estroboscopia donde le diagnostican lesión bilateral congénita en cuerdas vocales tipo sulcus glottidis, con severo defecto de cierre glótico de unos 2 milímetros en toda la longitud del espacio glótico y ausencia de espacio de Reinke.

Fue derivada a rehabilitación, pero dada de alta por no mejoría con el tratamiento logopédico, por ser este ineficaz.

El otorrinolaringólogo propuso relleno con grasa autóloga, que finalmente descarta tras la realización del PRAAT ${ }^{(5,6)}$ (análisis de voz, en base al estudio espectrográfico, donde se evalúan parámetros como la frecuencia fundamental y sus armónicos, el grado de perturbación del tono y la intensidad y el nivel de energía del ruido analizado).

Se la valoró con el "Índice de capacidad vocal"(7) (instrumento validado para la valoración del menoscabo asociado a la disfonía que percibe el paciente: a mayor puntuación mayor es el efecto discapacitante) obteniendo 84 puntos de 120, considerándolo como disfonía severa.

También se valoró la cirugía, descartándose la misma por no poder ofrecer garantías suficientes de mejoría, dada su patología (lesión atrófica bilateral con retracción, voz no funcional y disfonía severa).

Durante el examen de salud presenta síntomas subjetivos de sensación de falta de aire al hablar y fatiga vocal. En cuanto al habla conversacional se aprecia ronquera, cambios de tono y menor potencia vocal. El ritmo conversacional es acelerado, la intensidad es media-baja, el tono medio es agravado, hiponasalidad, coordinación fono-respiratoria deficiente agotando el aire, voz soplada y timbre laríngeo.

Se la considera "Apta con limitaciones a no realizar tareas que requieran atención al público mantenida". Tras realizar la evaluación de riesgos específica de su puesto y analizar todos los puestos disponibles de la empresa, se concluye que las tareas que requieren la utilización de la comunicación verbal suponen entre un 80$85 \%$ de su jornada, y son consideradas esenciales, por lo que se procede a despido objetivo por ineptitud sobrevenida. 


\section{Discusión}

La disociación entre el profesiograma y las tareas específicas que realizan los trabajadores no permite una evaluación integral de los mismos, lo que constituye un problema para los trabajadores que puedan quedar en un limbo sin prestación ni trabajo(1,8).

La trabajadora del caso presenta un cuadro infrecuente sin tratamiento conocido ni mejoría posible, y sin posibilidad de ejercer su profesión habitual en la empresa ni en otras de características similares, al no tener un nivel conversacional eficaz.

Por todo ello, consideramos que es necesario considerar cambios a varios niveles:

- Un cambio en lo que se considera como profesión habitual,

- Una valoración de la incapacidad con una determinación objetiva de las exigencias del trabajo,

- Una reformulación de la incapacidad permanente, objetivando la posibilidad de conversión a una compensación transitoria larga, para facilitar la incursión laboral en otro trabajo.

Y a nivel general, se pone de manifiesto la necesidad de un canal de comunicación eficaz entre las partes implicadas con un flujo de información compartida entre el ámbito laboral, asistencial, así como una valoración de la capacidad/incapacidad laboral de modo multidisciplinar, contemplando de forma integrada el diagnóstico, el tratamiento, la evolución, la perspectiva preventiva y la laboral.

\section{Bibliografía}

1. Vicente J. No apto pero no incapacitado. La controversia del ser o no ser. Med Segur Trab. 2017;63:131-58.

2. Asociación Española de Especialistas en Medicina del Trabajo. [página principal en Internet] [citado 21 oct 2019]. Incapacidad y discapacidad: diferencias conceptuales y legislativas. Disponible en: http://www.aeemt.com/web/

3. Guía de valoración de incapacidad laboral temporal para médicos de atención primaria. Instituto de salud Carlos III, Asociación Nacional Médicos del Trabajo en Ámbito Sanitario; 2015.

4. Real Decreto Valoración de Discapacidad. RD No 1971/1999 (23 Dic 1999).

5. Boersma P, van Heuven V. Speak and unSpeak with PRAAT. Glot International. 2001;5:341-347.

6. Boersma P, Weenink D. Praat: doing phonetics by computer [página principal en Internet]. Phonetic Sciences, Universitty of Amsterdam [citado 21 ene 2020]. Disponible en: http://www.fon.hum.uva.nl/praat/ 
7. Jacobson BH, Jonson A, Grywalski C, Silbergleit A, Jacobson G, Benninger MS, et al. The Voice Handicap Index (VHI): development and validation. Am J Speech Lang Pathol. 1997;6:66-70.

8. Vicente J. La valoración de la profesión, del trabajo, de la ocupación, y de las tareas en el procedimiento de valoración de la capacidad laboral en materia de seguridad social. Med Segur Trab. 2014;60:660-674. 